\title{
SOBRE POSITIVISMO JURÍDICO, UNA VEZ MÁS
}

\author{
Miguel Ángel Rodilla \\ Universidad de Salamanca
}

\section{INTRODUCCIÓN}

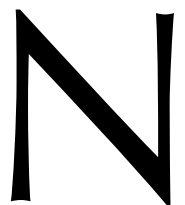

o es un secreto que desde hace décadas el positivismo jurídico ha entrado en una crisis de identidad. Tras la ofensiva liderada por Ronald DwORKIN, el reparto de la herencia de HART ha conducido a una situación en la que la multiplicación de variantes del positivismo ha ido acompañada de una difuminación de los contornos. Liborio HiERRO y

Paco LAPORTA parecen adscribirse a la posición conocida como «positivismo normativo», que tiene en Tom CAMPBELL el representante más conspicuo. No puedo entrar a discutir esa posición ni la forma como HIERRO y LAPORTA se insertan en ella. Afortunadamente, en su instructivo trabajo «¿Por qué ser positivista?» (Doxa 25, 2002) HIERRO ha formulado de un modo directo y muy articulado su posición. Tomando pie en ese artículo volveré sobre la fatigada discusión en torno al positivismo. Ateniéndome a la caracterización que ofrece HIERRO, esbozaré unos pocos comentarios, no con la intención de rebatir sus argumentos sino más bien de continuar su reflexión hasta un punto en el que tal vez tenga sentido suscitar la pregunta ¿por qué seguir auto-etiquetándose como positivista?

\section{TRES TESIS}

«Positivismo jurídico» es el cómodo rótulo con el que designamos un conjunto variado de doctrinas que presentan diferencias importantes en presupuestos y tesis. Mediado su artículo (pp. 279 y ss.), HIERRO, con el fin de definir su objeto, formula en los siguientes términos tres tesis que él considera características del positivismo jurídico:

1. la «tesis social», conforme a la cual «el derecho es un fenómeno de origen social o, dicho de otro modo, [...] las fuentes del derecho son meramente convencionales»;

2. la «tesis de la identificación», conforme a la cual «las proposiciones sobre la existencia de un sistema jurídico y las proposiciones sobre la existencia de una norma jurídica son proposiciones meramente descriptivas y, por ello, veritativas»; y finalmente,

3. la «tesis de la separación», conforme a la cual entre derecho y moral solo puede haber a lo sumo una conexión contingente: «no hay ninguna conexión necesaria 
entre el derecho y la moral» de modo que «la afirmación de que algo es derecho no contiene necesariamente ningún juicio de valor».

HIERRO caracteriza la primera como una «tesis ontológica», la segunda como una «tesis gnoseológica» y la tercera como una «tesis axiológica».

\section{TRES COMENTARIOS}

No resulta enteramente claro si hemos de tomar esas tres tesis como tesis características del positivismo o más bien como tesis minimas que una teoría necesita defender conjuntamente para poder ser catalogada como positivista. Más adelante volveré incidentalmente sobre este punto. Sin entrar de momento en él, voy a comentar brevemente cada una de esas tesis, añadiendo algunas puntualizaciones que, si son correctas, tal vez nos sitúen ante un horizonte teórico más allá del positivismo.

\subsection{La tesis social}

No tengo dificultad en aceptar la tesis de que el derecho es un fenómeno de origen social, una entidad convencional — siempre que se añada que no es un fenómeno puramente convencional, una convención pura, y que, aunque sus reglas son convencionales, no son (necesariamente) convenidas-.

Para aclarar este punto puede ser instructiva la comparación entre el derecho y los juegos. Por una parte, los juegos son convenciones puras, entidades puramente convencionales: sus reglas son enteramente arbitrarias y regulan actividades construidas por el juego mismo y que no existen fuera del universo del juego. Eso explica que la posibilidad de crear juegos sea virtualmente infinita; y que muy a menudo entre las reglas de diferentes juegos no haya semejanzas en cuanto al contenido. El derecho, en cambio, no puede ser concebido como una convención pura en este sentido, si por derecho entendemos el sistema normativo «supremo» de una sociedad (J. RAZ), con autoridad para regular todas los aspectos de la vida humana susceptibles de ser regulados por normas. Sin necesidad de afirmar que es una entidad natural, el derecho está muy estrechamente vinculado a las exigencias de la reproducción social de la vida humana, y eso parece imponerle ciertas exigencias en cuanto al contenido. La doctrina de HART sobre el «contenido mínimo del derecho natural», que tantos malentendidos ha suscitado, llama la atención sobre este punto. Por otra parte, la participación en los juegos es voluntaria, y el sometimiento a sus reglas está libremente asumido. En cambio, quienes están sujetos a un sistema jurídico lo están incluso contra su voluntad, aunque no acepten sus reglas.

Esta puntualización a la «tesis social» es casi trivial, pero no carece de consecuencias. El carácter puramente convencional y voluntario acoraza a las reglas de los juegos frente a la crítica moral: las reglas de los juegos pueden ser complejas o estúpidas, estimulantes o aburridas, pero carece de sentido preguntarse si son justas o injustas para los jugadores. Como es sabido, una caracterización del derecho como convención pura, precisamente como un juego, condujo a HOBBES a negar que la cuestión de la justicia sea aplicable a las normas jurídicas: «ninguna ley puede ser injusta. La ley es hecha por el poder soberano, 
y todo cuanto hace tal poder está autorizado por cada uno de los que integran el pueblo, que lo toman como cosa suya; y nadie puede decir que es injusto lo que todos toman de este modo. Con las leyes de una república ocurre como con las leyes del juego: nada de lo que acuerden todos los jugadores es injusto para ninguno de ellos» (Leviatán, cap. 30). Pero a diferencia de los juegos el derecho no es una entidad puramente convencional, ni sus reglas son (necesariamente) asumidas de forma voluntaria por quienes están sometidos a ellas. Que ostente la pretensión de regular de forma comprehensiva la conducta humana y se imponga a las personas contra su voluntad explica que el derecho esté permanentemente sujeto a la cuestión de la justicia: determina de modo tan decisivo las expectativas vitales de las personas que le es inherente la pretensión de justicia y está crónicamente sujeto a la presión de la justificación moral. Pero aceptar esto no compromete en modo alguno a defender la tesis de que la justicia forma parte de las condiciones de validez del derecho, de modo que «derecho justo» sería una expresión redundante y «derecho injusto» una contradicción en los términos: «pretensión de justicia» no es «justicia».

\subsection{La tesis de la identificación}

Afirmar que las proposiciones sobre la existencia de las normas jurídicas son «meramente descriptivas y por ello veritativas» subestima el papel de la interpretación en el derecho.

Tal como HiERro la formula, su segunda tesis se ajusta a la distinción kelseniana entre Rechtsnorm y Rechtssatz, entre «norma jurídica» y «proposición jurídica»: las normas jurídicas, en cuanto oraciones deónticas, no son accesibles a la cuestión de la verdad; en cambio, las proposiciones jurídicas, que KELSEN concibe como aserciones sobre la existencia (validez) de las normas jurídicas, pueden, como todo enunciado asertórico, ser discutidas como verdaderas o falsas. Esta distinción tiene, entre otras, la función de asegurar la pretensión de verdad (y la sujeción a los principios lógicos) de la ciencia jurídica sin necesidad de trasladarla al sistema jurídico mismo. Ahora bien, entendida en estos términos, la tesis de la identificación es simplificadora, en la medida en que pasa por alto la distinción entre disposición jurídica y norma jurídica ${ }^{1}$. Las normas jurídicas no se leen inmediatamente en los textos legales, sino que son el resultado de procesos de interpretación de las disposiciones jurídicas emitidas por los órganos de producción del derecho. Entre los enunciados normativos producidos por el legislador y las normas jurídicas media, pues, un proceso de interpretación. Pero una vez que se admite esto, la concepción puramente descriptivista de las proposiciones jurídicas (y de la ciencia jurídica) se vuelve problemática.

Identificar los actos de producción de normas y las disposiciones jurídicas puede ser una tarea relativamente sencilla —una tarea que concluye, por cierto, en la formulación de proposiciones «meramente descriptivas y por ello veritativas». La presencia de desacuerdos teóricos a propósito del derecho vigente, que son moneda corriente entre los juristas, indica que identificar las normas que forman parte del sistema requiere poner

1 Vid. R. GuAstini, Dalle fonti alle norme, Torino, Giappichelli, 1990 (cap. 1) y Distinguiendo, Barcelona, Paidós, 1993 (cap. 2 de la segunda parte); sobre la relevancia de esa distinción para la teoría de la interpretación, vid. también L'interpetazione dei documenti normativi, Milano, Giuffrè, 2014 (espec. caps. V y VII). 
en marcha un complejo proceso de interpretación en el que inevitablemente entran en juego razones justificatorias subyacentes. Las reflexiones de DwORKIN sobre la forma como los jueces resuelven los «casos difíciles» indican que de forma expresa o tácita ese proceso de interpretación está gobernado por principios que, incluso cuando han sido reconocidos por el legislador, no son propiamente convencionales. Y, frente a una opinión bastante extendida, creo que esto vale no solo para los casos difíciles y en el marco de sistemas jurídicos que explícitamente reconocen principios morales como normas superiores: por un lado, casos fáciles son aquellos en los que no se presenta conflicto entre las reglas y sus justificaciones implícitas y por eso los principios subyacentes pueden quedar latentes en el proceso de interpretación ${ }^{2}$; por otro, en los sistemas jurídicos en los que el legislador no reconoce explícitamente principios el recurso a principios implícitos es inevitable, si es que lagunas y antinomias han de resolverse en el marco del sistema.

En estas condiciones la tesis de la identificación, tal como la formula HIERRO, es vulnerable. Pero en realidad no resulta claro que HIERRO mismo la acepte. En efecto, examinando la posición del llamado «positivismo inclusivo» él mismo parece ponerla en duda: «creo que la validez de las normas puede presentar un carácter controvertido en cualquier sistema jurídico y no solo sobre la base de su confrontación con un punto de vista moral» (292); y más adelante afirma que es «dudosa» la «posibilidad de construir una Ciencia del Derecho meramente descriptiva y libre de valoraciones» (298). Si esto es así, se diría que podemos eliminar la tesis de la identificación del catálogo de tesis mínimas del positivismo.

\subsection{La tesis de la separación}

HIERRO considera la tesis de la separación entre derecho y moral como la tesis fundamental del positivismo: «constituye la base de las otras dos» (p. 280). De hecho es en ella en la que centra su atención. Pero es interesante señalar que la caracteriza como una tesis axiológica y no primariamente como una tesis ontológica: «la tesis de la separación se sostiene en un sentido ético normativo, que [...] formula un observadorcrítico o un participante desde un punto de vista moral propio o crítico [...] La tesis de la separación es una tesis fundamentalmente axiológica y no, como con mucha frecuencia se entiende, una tesis ontológica» (p. 284). Esta afirmación resulta sorprendente, pues si no es una tesis ontológica sino axiológica, la tesis de la separación no nos dice nada sobre el derecho sino más bien sobre cómo debemos conducirnos en relación con él. Se diría, pues, que hemos de interpretarla como una tesis de teoría moral más que de teoría del derecho: hay razones morales para que en nuestro trato con el derecho (en particular, en los procesos de aplicación de normas) debamos concebirlo como independiente de la moral, incluso si realmente no lo fuera.

Ahora bien, si no fuera posible defender la tesis de la separación como tesis ontológica ¿puede ser aceptable como tesis axiológica? ${ }^{3}$. Y si, por el contrario, es acepta-

2 Vid. M. AtienZa y J. Ruiz MANERo, «Sobre principios y reglas», Doxa, núm. 10, 1991, 117.

3 Por lo demás, si la tesis de la separación no es una tesis ontológica sino axiológica, y es «la base» de las otras dos tesis, chemos de entender que en algún sentido la tesis social y la tesis de la identificación se fundamentan en consideraciones morales? 
ble como tesis ontológica, ¿no resulta innecesario defenderla como tesis axiológica? No voy a ocuparme de estas preguntas. Más me interesa entender la posición de HIERRO. Al caracterizar la tesis como «tesis axiológica», HIERRO parece querer defender al mismo tiempo la conexión y la separación de derecho y moral. Para disolver la apariencia paradójica de esta formulación basta con introducir la distinción entre moral positiva y moral crítica. Y entonces la tesis reza: el derecho está conectado con la moral positiva y separado de la moral crítica (o, en una versión más débil, conectado solo contingentemente con ella). Como ya he dicho, a todo sistema jurídico le es inherente una pretensión de justicia. Esto no significa que encarne tales o cuales principios morales, sino que encarna alguna concepción moral particular. En este sentido el derecho está conectado a la moral —solo que a una moral positiva. HIERRO avala explícitamente esta conclusión ${ }^{4}$. Pero que el derecho positivo esté conectado a una moral positiva no impide que siga abierto a la crítica moral. En este sentido está separado de la moral — solo que de la moral crítica de quien observa el sistema sin comprometerse con él一. Así pues, si mi interpretación es correcta, al caracterizar la tesis de la separación como tesis axiológica HIERRO quiere preservar la separación entre el derecho y la moral crítica, aceptando en cambio la conexión entre el derecho y la moral positiva.

Para precisar un poco más hay que introducir una puntualización a propósito de la distinción, no poco confusa, entre moral positiva y moral crítica. Esa es más una distinción de perspectivas que de contenidos normativos. Al comienzo dije que el derecho positivo no es un conjunto de convenciones puras. Ahora he de añadir que tampoco lo es la moral positiva. Si entendemos la moral positiva precisamente como moral y no como una mera colección de convencionalismos sociales, le es inherente una pretensión de rectitud que actualizan continuamente quienes están sujetos a ella como participantes desde el punto de vista interno: a estos se impone con la fuerza de lo incondicional. Pero naturalmente la pretensión de rectitud de las normas de una moral positiva puede resultar injustificada desde el punto de vista de aquel que la considera críticamente.

Esto explica una peculiaridad de la situación normativa de los tribunales. Cuando aplican las normas jurídicas, los tribunales tienen que adoptar frente al derecho la actitud interna del participante-aceptante; en particular, tienen el deber institucional de tomarse en serio los principios internos del sistema en su condición de principios morales genuinos y no de meras convenciones. Y precisamente por eso, en el ejercicio de su función, quienes ocupan esos órganos han de dejar al margen los principios morales que ellos mismos, como ciudadanos, consideran correctos, y que desde la perspectiva del observador pueden esgrimir críticamente contra las normas vigentes. En este sentido los órganos de aplicación del derecho tienen que actualizar en su práctica institucional la conexión y al mismo la diferenciación entre derecho y moral.

${ }^{4}$ En pp. 280 y ss. considera contraintuitivas las tesis: (1) de que puede existir algún «sistema jurídico que no incluya entre sus normas ninguna creencia y/o regla de la moralidad positiva de esa sociedad» y (2) de que puede existir «algún sistema jurídico sin que exista alguna creencia y/o regla de la moralidad positiva de esa sociedad [...] que establezca la obligación moral [...] de obedecer las normas jurídicas». «Ambas afirmaciones — dice HIERRO— parecen contradecir toda la evidencia empírica disponible». 


\section{CODA}

Como ya he señalado, en el abigarrado panorama del positivismo posthartiano Liborio HIERRO y Paco LAPORTA engrosan las filas de lo que conocemos como «positivismo normativo» o «positivismo ético». Pero, si no interpreto erróneamente, defienden el positivismo por razones ligeramente diferentes.

HIERRO lo defiende porque cree que mantener viva la conciencia sobre la separación del derecho y la moral facilita una actitud crítica frente al derecho positivo: «La gran virtualidad de la tesis de la separación no estriba, ni solo ni principalmente, en la dudosa posibilidad de construir una Ciencia del Derecho meramente descriptiva y libre de valoraciones, sino en la posibilidad de mantener un punto de vista moral frente al Derecho positivo libre de determinaciones fácticas» (298). LAPORTA, en cambio, ve en el positivismo jurídico una defensa contra una moralización espuria, no ya del derecho mismo sino de la práctica de aplicación del derecho, especialmente por los jueces - una moralización que en su opinión pone en peligro el principio del imperio de la ley, y con ello la seguridad jurídica y la predecibilidad de las consecuencias de las acciones de los individuos, dañando su autonomía; y bajo el rótulo de «ética del legalismo» ${ }^{5}$, apoya su defensa del positivismo en los principios políticos de un Estado democrático de derecho, en particular en el principio de la soberanía popular y la división de poderes. En ambos casos en su defensa del positivismo, precisamente en su variante normativa, LAPORTA y HIERRO enlazan con los impulsos políticos y morales de la ilustración.

La pregunta que dejaré formulada, para terminar, es si en el contexto actual la invocación del positivismo es todavía necesaria como signo de fidelidad a los ideales de la ilustración. Desde finales del siglo XVIII el positivismo jurídico se autodefinió reactivamente por oposición al iusnaturalismo y su concepción metafísico-teológica del derecho. Entre tanto el panorama yusfilosófico se ha transformado de tal modo que es inevitable preguntarse si la alternativa «o iusnaturalismo o positivismo» está ya a la altura de la elaboración teórica alcanzada. Por lo demás, una vez que el iusnaturalismo está en franco retroceso, declararse positivista ¿frente a qué?, ¿frente a corrientes, como las denominadas «principialismo» $\mathrm{y}$ «(neo)constitucionalismo», que se mueven en un espacio que se encuentra más allá de la vieja alternativa? Cuando las tesis positivistas se han visto forzadas a reformularse una y otra vez, y han encarnado en tantas variantes enfrentadas entre sí, ¿̇tiene sentido seguir insistiendo en proclamarse positivista? ¿Por qué no discutir los problemas desentendiéndose de etiquetas que ya resultan simplificadoras?

5 Incidentalmente LAPORTA ofrece una caracterización apretada de su posición como «positivismo normativo, positivismo ético, o [...] ética del legalismo» (El imperio de la ley, Madrid, Trotta, 2007, 151), haciendo equivalentes etiquetas que no apuntan exactamente en la misma dirección.

$\triangle \quad$ DOXA EDICIÓN ESPECIAL (2017) 